\title{
Maternal Reminiscing Style and Children's Developing Understanding of Self and Emotion
}

\author{
Robyn Fivush
}

Published online: 28 November 2006

(C) Springer Science+Business Media, LLC 2006

\begin{abstract}
Individual differences in how mothers structure reminiscing about shared past experiences with their preschool children are related to children's developing autobiographical memory skills and understanding of self and emotion. More specifically, mothers who engage in highly elaborative reminiscing have children who come to tell more coherent and emotionally expressive autobiographical narratives, and these children also show better understanding of self and are better able to regulate emotion than children of less elaborative mothers. This body of research is reviewed and relations between maternal reminiscing style and children's developing self and emotional understanding are explicated.
\end{abstract}

Keywords Reminiscing - Autobiographical memory $\cdot$ Self $\cdot$ Emotion

Remembering is a social activity. Whether recounting the details of our day over the dinner table, laughing over told and retold stories with friends and family, or meeting new acquaintances, we all talk about the experiences of our lives, and these stories of our past define who we are (Fivush, 1988; McAdams, 2001).

This paper was written while the first author was a senior fellow in the Center for the Interdisciplinary Study of Religion at Emory University, sponsored by a grant from The Pew Charitable Trusts. The opinions expressed here are those of the authors and do not necessarily reflect the views of The Pew Charitable trusts.

R. Fivush $(\bowtie)$

Department of Psychology, Emory University, 532 N. Kilgo

Circle, Atlanta, GA 30322, USA

e-mail: psyrf@emory.edu
Most intriguing, it is through sharing these stories with others that these memories take on personal meaning for the self. Through shared reminiscing, we re-interpret and re-evaluate our past experiences in ways that create new meaning. Thus autobiographical reminiscing is a critical process in how we come to understand who we are in the world. In essence, through autobiographical narratives constructed in social interaction, we create personal meaning and emotional understanding of the events we have experienced that contributes to our evolving sense of self throughout the lifespan.

Intriguingly, this process begins very early in development, as displayed in Table 1. Virtually as soon as children begin to talk, at about 16- to 18-months of age, they begin to participate in talk about the past, but at this early stage, children make few and fleeting references to the past. They soon become able to respond to parental questions about past events with simple answers and confirmations. Between 3 and 5 -years of age, children are able to engage in more detailed conversations about the past, but they are still reliant on adults to provide most of the structure and content. By the end of the preschool years, children are able to give a relatively coherent account of a past event on their own. Research over the past 20 years has examined this developmental process, charting relations between early parent-child reminiscing and children's emerging abilities to provide coherent autobiographical narratives (see Fivush, Haden, \& Reese, in press; Nelson \& Fivush, 2004, for reviews). This research documents individual differences in how parents structure early reminiscing, often related to gender, that provides insights into how individuals come to understand their own personal experience 
Table 1 Development of children's ability to participate in reminiscing

\begin{tabular}{ll}
\hline Age & Ability to engage in conversations about the past \\
\hline $\begin{array}{cl}18- \\
20 \text { months }\end{array}$ & Beginning reference to immediate past \\
$20-$ & Simple responses to parental questions \\
36 months & \\
3-5 years & Participation in parent-guided reminiscing \\
5-6 years & Individual narratives \\
\hline
\end{tabular}

throughout the lifespan. But children are learning more than how to narrate their past in early parentguided reminiscing; individual differences in parental reminiscing style is related to the quality of the parentchild emotional relationship, and through creating personal meaning, parent-child reminiscing contributes to children's developing understanding of emotion and of self.

Autobiographical narratives are linked to selfunderstanding in at least three ways, in terms of selfdefinition, self-in-relation and self-regulation (Fivush, Berlin, Sales, Mennuti-Washburn, \& Cassidy, 2003). In terms of self-definition, we construct a sense of self at least partly in terms of the kinds of experiences we have had and how we understand these experiences. Moreover, autobiographical memory is not a series of isolated memories of past events; we construct an identity through coalescing our experiences into an integrated coherent life narrative (McAdams, 2001). In terms of self-in-relation, through reminiscing we create a shared past in which our lives are intertwined with others in personally meaningful ways (Fivush, Haden, \& Reese, 1996). Finally, in terms of self-regulation, through creating coherent, expressive and explanatory narratives of our experiences, we come to understand and regulate our emotional life (Fivush \& Sales, 2006; Pennebaker, 1997).

In this review, I describe individual differences in parental reminiscing style and children's developing autobiographical memory skills. The majority of this research focuses on mostly white middle class mothers and their preschool children living within traditional families in western cultures. A few studies have examined fathers, as well as older children, and this research will be discussed where available. To date, very little research has examined the roles of siblings or extended family members (but see Pratt \& Fiese, 2004) or class differences (but see Burger \& Miller, 1999; Melzi \& Fernandez, 2004), and none have examined non-traditional families.

There is however a growing body of research examining cultural differences in parent-child reminiscing (see Fivush \& Haden, 2003; Fivush et al., in press, for overviews). As personal narratives are integral to how we make sense of our selves and the world, the way in which cultures conceptualize self should play a critical role in the content and structure of parent-child reminiscing. Most of the research has focused on differences between western cultures, which view self as autonomous and independent, and eastern cultures which view self as collective and interdependent (Leichtman, Wang, \& Pillemer, 2003; Wang, 2001), and this research will be integrated into the review. However, again, little research has examined within culture class differences, or taken a truly multicultural approach, examining multiple cultures varying along specified dimensions that would be theoretically relevant to mother-child reminiscing. These are all clearly important limitations, and I will return to these issues when I discuss the implications of the research findings.

In the first section, I discuss differences between high and low elaborative reminiscing. I then discuss the emotional content of mother-child reminiscing and review research showing relations between motherchild emotional attachment and reminiscing, as well as relations between reminiscing and children's emerging emotional understanding. The next section highlights gender differences, describing maternal reminiscing with daughters vs. sons, and the following section focuses more closely on how mothers and children reminisce about highly stressful events, and relations between this and children's coping skills. Throughout, relations between mother-child reminiscing, children's emerging autobiographical memory skills, and children's developing understanding of self and emotion are underscored, and these threads are woven together in the final section, in which implications of autobiographical reminiscing and self-understanding are discussed more fully.

\section{Maternal Reminiscing Style}

Whereas virtually all mothers (at least in modern societies) reminisce with their young children about the experiences they shared together, there are clear and enduring differences in this process. Although different studies have used somewhat different methodologies, either collecting spontaneous conversations between mothers and children or eliciting conversations about past events, the research has converged on elaboration as a critical dimension along which mothers vary (Fivush \& Fromhoff, 1988; Fivush et al., in press; Hudson, 1990; Nelson \& Fivush, 2004). High elaborative 
mothers talk frequently about the past, and engage in long and detailed conversations about what happened. Low elaborative mothers, in contrast, do not talk about the past as frequently and when they do, they tend to ask few and redundant questions, as these examples illustrate. The first example is a highly elaborative mother reminiscing with her 40-monthold son:

Mother: Remember when we first came in the aquarium? And we looked down and there were a whole bunch of birdies...in the water? Remember the name of the birdies?

Child: Ducks!

Mother: Nooo! They weren't ducks. They had on little suits. (pause) Penguins. Remember what did the penguins do?

Child: I don't know

Mother: You don't remember?

Child: No

Mother: Remember them jumping off the rocks and swimming in the water?

Child: Yeah

Mother: Real fast. You were watching them jump in the water, hmm?

Child: Yeah

Here we see that the child is engaged in the conversation although not recalling any accurate information. With each additional question, the mother provides additional information such that by the end of this excerpt, there is a sense of story, a coherent account of seeing the penguins at the aquarium. Even though children in the early preschool years contribute little to these conversations, highly elaborative mothers continue the conversation, adding more and more detail with each additional question, inviting their children to share this past experience with them. In essence highly elaborative mothers create rich coherent stories of the shared past with their children. Contrast this with the next example of a low elaborative mother and her 40-month-old.

Mother: What kind of animals did you see, do you remember?

Child: Lollipops

Mother: Lollipops aren't animals, are they? Who, what kind of animals did you see?

Child: Giraffe.

Mother: You saw giraffes? And what else?

Child: RRROAR!

Mother: What's roar?

Child: Lion

Mother: What else did you see?
Child: ROAR!

Mother: What else did you see?

As can be seen, this mother does not seem interested in creating a rich story of what she and her child experienced together. Even when the child recalls some information, the mother does not follow in and elaborate on this; she does not discuss what the lion sounded like or looked like. Rather she seems focused on having her child recall specific pieces of information about the event. There is no sense of story here, only attention to isolated details. Thus, highly elaborative mothers work to weave a coherent narrative of the shared past to a greater extent than do low elaborative mothers.

Importantly, mothers are consistent over time and over siblings in their level of elaboration. Mothers who are highly elaborative early in their children's development remain highly elaborative as their children grow older (Harley \& Reese, 1999; Reese, 2002; Reese, Haden, \& Fivush, 1993), and mothers who are highly elaborative with one child, are also highly elaborative with their other children (Haden, 1998). However, maternal elaboration is not consistent across different conversational contexts. Mothers who are highly elaborative during reminiscing are not simply more "talkative." They do not talk more during free play, mealtime, or other caregiving activities (Haden \& Fivush, 1996; Hoff-Ginsburg, 1991), indicating that reminiscing is a unique conversational context in which mothers may be trying to achieve specific goals with their children.

In line with this interpretation, research has demonstrated that children of more highly elaborative mothers participate to a greater extent in reminiscing both concurrently and over time (e.g., Bauer \& Burch, 2004; Farrant \& Reese, 2000; Fivush \& Vasudeva, 2002; Flannagan, Baker-Ward, \& Graham, 1995; Haden, 1998; Harley \& Reese, 1999; Hudson, 1990; Peterson, Jesso, \& McCabe, 1999; Peterson \& McCabe, 1992; Welch-Ross, 1997). By the end of the preschool years children of more highly elaborative mothers are providing more detailed, more coherent narratives of their personal experiences both in conversations with their mother and with an unfamiliar adult. Further, these relations are specific to reminiscing. Again, it is not simply that mothers who talk more have children who talk more, but that mothers who engage in highly elaborative reminiscing have children who learn these specific narrative skills, and these narrative skills are only minimally related to children's more general language abilities (Reese \& Brown, 2000; Reese et al., 1993). The longitudinal patterns indicate that children 
are learning how to represent and narrate their past in early mother-guided reminiscing, and that children of highly elaborative mothers are developing more elaborated, more coherent memories of their past.

Research has also begun to examine these questions cross-culturally, and the findings indicate that mothers from Western middle-class cultures are on the whole more elaborative during past event conversations than mothers from non-Western cultures, such as middleclass Maori (Hayne \& MacDonald, 2003; MacDonald, Uesiliana, \& Hayne, 2000), Korean (Mullen \& Yi, 1995), Indian (Leichtman et al., 2003), and Chinese (Wang, 2001) families (see Fivush \& Haden, 2003, for a review). The general consensus is that because eastern cultures are more collectivistic than western cultures, they engage in less self-focused reminiscing. Indeed, by middle childhood, children in eastern cultures tell less elaborated and detailed stories of their personal past than do western children (Han, Leichtman, \& Wang, 1998), and this difference persists through adulthood (Pillemer, 1998). These finding suggest that cultural values of having and telling personal narratives influences the cultural practice of reminiscing. However, it is also important to point out that, although nonWestern mothers may, on the whole, reminisce less elaboratively with their children than do Western mothers, there is still variability along the dimension of elaboration, with some mothers being more elaborative than others, and these differences are related to children developing personal narratives (Mullen \& Yi, 1995; Wang, 2001).

\section{Emotional Content of Mother-Child Reminiscing}

Highly elaborative mothers also include more emotional information in their reminiscing, information that focuses not just on what happened but on what the event means. It is our thoughts and feelings about what happened that make this event personally meaningful. By reminiscing about how and what the child and others felt about the event, mothers are helping children to evaluate and understand this event from their own personal perspective, and in relation to others' perspectives. However, there may be different underlying goals when reminiscing about positive vs. negative experiences. When mothers and children reminisce about highly positive family events, such as family outings and vacations, holidays and family reunions, it makes sense that mothers may be trying to create a shared emotional history with their children; by telling and re-telling the positive events that we have shared in the past, we create a sense of shared history that creates emotional bonds through time. In contrast when discussing negative experiences, mothers may have different underlying goals that of helping their children to understand and resolve negative affect, as this example of a mother and her 4-year-old daughter illustrates. Mother and child are discussing what happened when the child's friend, Malika, spent the night:

Mother: I remember when you were sad. You were sad when Malika had to leave on Saturday, weren't you?

Child: Uh-huh.

Mother: You were very sad. And what happened? Why did you feel sad?

Child: Because Malika, Malika say, was having (Unintelligible word)

Mother: Yes.

Child: And then she stood up on my bed and it was my bedroom. She's not allowed to sleep there.

Mother: Is that why you were sad?

Child: Yeah. Now it makes me happy. I also, it makes me sad. But Malika just left.

Mother: Uh-huh.

Child: And then I cried.

Mother: And you cried because....

Child: Malika left.

Mother: Because Malika left? And did that make you sad?

Child: And then I cried (makes "aaahhhh" sounds) like that. I cried and cried and cried and cried.

Mother: I know. I know. I thought you were sad because Malika left. I didn't know you were also sad because Malika slept in your bed.

Here, we see that mother and child are focused on how the child felt, both about her friend sleeping in her bed and her friend leaving the next morning. At first, mother and child disagree about the child's emotional reactions, but the mother does not dismiss her child's rendition; she pays careful attention and draws the child out, ultimately helping the child to understand and integrate her multiple feelings about the event. In this way, highly elaborative mothers are helping their children not just to understand what happened, but to understand their feelings about what happened and to help evaluate the event from the child's personal perspective. Thus highly elaborative mothers are helping their children to build connections between past experiences and present understanding, and in this way making explicit links between the past and present self.

In addition, highly elaborative mothers may be concerned with creating a richly detailed shared history with their children in the service of maintaining 
emotional bonds. This interpretation is supported by findings that mothers who are more elaborative during reminiscing have children with more secure attachment relationships (Fivush \& Reese, 2002; Fivush \& Vasudeva, 2002; Laible, 2004a; Reese \& Farrant, 2003). Attachment is a foundational construct in developmental psychology that assesses the emotional bond between mother and child (Bowlby, 1969). Children who receive more responsive and sensitive caregiving come to believe the world is a safe place, that others are trustworthy, and that they, themselves are worthy of care. In contrast, children who receive less sensitive and responsive caregiving come to believe the world is not a safe place, that others are not trustworthy and they are not worthy of care. Early attachment is based on children's sensory experiences, but with development, children develop explicit internal working models, that provide representations of self, of other and of the world. A more secure attachment relationship allows the child to feel safe in exploring the world, knowing that they have a safe haven to return to in times of stress.

Several theorists have argued that a more secure attachment relationship will also allow for more fluid communication between mother and child, as children begin to explore the boundaries of both their external and internal world through language (Bretherton \& Mulholland, 1999; Thompson, 2000). Because the reminiscing context is one in which mothers and children are exploring what happened, and what it means, more securely attached dyads will be better able to discuss, negotiate and elaborate on what happened, and especially the emotional content of past experiences. Indeed, more securely attached mother-child dyads reminisce in more highly elaborated ways, especially about emotions (Farrar, Fasig, \& Wech-Ross, 1997; Laible, 2004b; Laible \& Thompson, 2000; Oppenheim, Nir, Warren, \& Emde, 1997).

Moreover, elaborated reminiscing is related to children's developing emotional understanding. Mothers who are more elaborative during reminiscing have children who display better emotional understanding and better emotional regulation on a variety of standardized assessments (Laible, 2004a, b). Further, research has demonstrated that the reminiscing context is more highly predictive of children's developing emotional understanding than other mother-child interaction contexts, such as book reading or talk about ongoing emotional conflicts (Laible, 2004b; Reese, Bird, \& Tripp, in press).

There are also cultural differences in mother-child emotional elaboration during reminiscing. Euro-American mothers are more elaborative and evaluative overall when reminiscing about emotions with their preschool children than are Chinese mothers, and they focus on causes and resolutions of emotional experiences more than Chinese mothers (Fivush \& Wang, 2005; Wang, 2001; Wang \& Fivush, 2005). These patterns suggest that Euro-American mothers are more concerned with helping their preschool children to understand and regulate their emotions than are Chinese mothers. Indeed, by early childhood, American children are more advanced in their emotional understanding than their Chinese age-mates (Wang, 2003). Overall, the results attest to the powerful influence that reminiscing about shared past experiences has on children's developing understanding of themselves and their world.

\section{Parental Reminiscing Style and Gender}

Intriguingly, reminiscing style is related to gender. In the few studies that have examined father-child reminiscing, findings indicate that fathers also vary along a dimension of elaboration as do mothers, and that both mothers and fathers are more elaborative with daughters than with sons, especially about emotions (Adams, Kuebli, Boyle, \& Fivush, 1995; Fivush et al., 2003; Kuebli \& Fivush, 1992; Reese, Haden, \& Fivush, 1996). Both mothers and fathers talk more about emotions overall when reminiscing with daughters, they mention more specific emotions words, they use a greater variety of emotions words (e.g., talking about being sad, upset, distressed, with girls, but only sad with boys), and they are more likely to talk about possible resolutions to negative emotions with daughters than with sons. Parents also place emotional experiences in a more social context with daughters than with sons (Buckner \& Fivush, 2000; Fivush, 1991, 1998). For example, a girl is sad because she cannot play with her friend whereas a boy is sad because he lost a favorite toy. Related to this, both mothers and fathers talk more about other people and relationships when reminiscing with daughters than with sons. These differences can be seen in the following excerpts; in the first, a mother is discussing what makes her 4-year-old daughter sad:

Mother: Well, one thing that made you really sad is when your best friend Shena moved away, right? Yeah, and did we watch all her things go on the moving truck? Uh-huh, and do you remember why she had to move away?

Child: ...Because Shena's Dad had to work.

Mother: Shena's Daddy was going to start working at a 
new job...And do you still miss Shena when you think about it? Yes?

Child: Yes.

Mother: It makes you sad. Doesn't it? But is she still your friend even far away? Yes! What can you do even though she's far away?

Child: Give her a happy letter with a (drawing) on it. Mother: Give her a happy letter, right, and we have a drawing, don't we?

Mother and child focus in on the loss of a relationship as an occasion for sadness, but the mother assures her child that even though her friend has moved far away, they can maintain the relationship, and provides one way to keep the relationship alive. In fact, it is obvious from this excerpt that this is something that the mother and child have discussed before and both are clearly sharing the emotional experience together. Contrast this with a conversation between a mother and her 4-year-old son about what makes him sad:

Mother: How did you feel when Mandy (the older sister) wouldn't let you play the other day, when she was playing with Jess and she told you boys to go away? How did that make you feel?

Child: Umm, sad.

Mother: And why does Mandy do that?

Child: Because she's mean.

Mother: (laughing) Is she mean? Is she mean all the time? When she doesn't let you play, you're not very happy, are you?

Child: ummm.

Mother: OK. (changes topic)

Although here again the cause of sadness is interpersonal, mother and child do not engage in an elaborated discussion of the emotional experience nor do they ever address what the child can do to resolve the negative affect. Through a focus on emotion, and especially through focusing on how and why emotions arise in life and how to cope with them, parents are placing girls' experiences in a more social emotional context than boys' experiences.

Although there are no gender differences in how girls and boys relate their past experiences early in the preschool years, but the end of the preschool years, girls are telling longer, more detailed and more emotionally rich narratives of their past than are boys (Buckner \& Fivush, 1998), and these gender differences remain relatively stable throughout development. As adults, females tell longer, more vivid, more emotional and more relationally oriented autobiographical narratives than males (Bauer, Stennes, \& Haight, 2003; Davis, 1990, see Fivush \& Buckner, 2003, for a review), suggesting that parental reminiscing style helps set the stage for gendered ways of understanding self.

Moreover, the focus on emotion, and especially the causes and resolutions to emotional experiences, in parent-daughter as compared to parent-son reminiscing may help girls better understand their emotional experiences. There is a good deal of evidence that girls are more advanced in emotional understanding in childhood than are boys; girls are able to label their own and others emotions better than boys at an earlier age, girls show more empathy than do boys, and girls are better able to regulate negative emotions than are boys (Brody, 1999). As adults, females report experiencing emotions more frequently and more intensely than do males, and females value emotional experience more than do males (see Fischer, 2000, for a review). However, the focus on emotion may also have some negative consequences. Both mothers and fathers focus a great deal more on sadness, discussing sadness almost three times as much with daughters than with sons (Fivush, Brotman, Buckner, \& Goodman, 2000; Fivush \& Buckner, 2000). Again, although there are no differences early in development, by middle childhood, girls are talking overwhelmingly more about sadness than are boys. It is possible that girls are learning to focus on sadness, and perhaps even to ruminate about sadness, in early parent-child reminiscing, to a greater extent than are boys, and this may inadvertently lead girls to a more ruminative, depressive style (Fivush \& Buckner, 2000; Nolen-Hoeksema, 2002).

\section{Reminiscing About Stressful Experiences}

Mother-child reminiscing about everyday negative experiences, such as sibling conflicts or lost toys, indicates that the ways in which mothers discuss these kinds of negative events with their young children is related to children's developing understanding of emotion. But what about more highly stressful events? Unfortunately highly stressful events befall us all, and the way in which we understand and evaluate these experiences is critical for subsequent well-being. Research with adults has shown that adults who are better able to report emotionally expressive and explanatory narratives of stressful experiences subsequently display higher levels of physical and psychological well-being (Pennebaker, 1997). Children do not yet have the narrative skills to form these coherent explanatory narratives on their own, and therefore may need the help of an adult. In the process of helping 
children form more expressive and explanatory narratives, parents may be helping their children to cope with their aversive experiences.

A few studies have begun to examine parent-child reminiscing about highly stressful events. Overall, mothers who are elaborative when reminiscing about emotionally positive events are also elaborative when reminiscing about highly negative experiences, such as accidents and injuries requiring emergency room treatment, or natural disasters (Ackil, Van Abbema, \& Bauer, 2003; Sales, Fivush, \& Peterson, 2003). However, when discussing positive experiences, mothers ask more closed-ended, yes/no questions, that simply require their children to confirm what happened, whereas when discussing negative experiences, mothers ask more open-ended, wh-questions, that require the child to recall and report some information about the event on their own. Likely, this reflects different underlying maternal goals in these two contexts. In reminiscing about positive events, mothers are focused on creating a shared history that maintains emotional bonds, and therefore telling a story such that mother and child will have a shared understanding of what occurred may be critical. In contrast, reminiscing about negative experiences may serve a more didactic function; mothers may be trying to help their children to understand how and why such experiences occur, and possibly help their children avoid such experiences in the future. To this end, mothers may be more focused on eliciting and formulating the child's understanding of the event.

In line with this interpretation, mothers talk more about the causes of negative events than of positive events (Ackil et al., 2003; Sales et al., 2003), and elicit more information about the causes of these events from their children. Most important, in research with somewhat older children, mothers who provide more emotionally expressive and explanatory narratives of aversive experiences with their 8- to 12-year-old children have children who display better coping skills, and fewer internalizing and externalizing behavior problems (Fivush \& Sales, 2006; Sales \& Fivush, 2005). Moreover, those mothers who themselves endorse more proactive coping strategies, such as active planning and cognitive restructuring, are better able to co-construct emotionally expressive and explanatory narratives of stressful events with their children (Fivush and Sales, 2006). These patterns, along with the previously discussed findings on attachment and reminiscing suggest that mother-child reminiscing emerges from and contributes to an ongoing motherchild socio-emotional relationship in which mothers who are more securely attached and can cope with aversive emotions more effectively are better able to discuss highly emotional and difficult experiences with their children in more open and explanatory ways, and that these co-constructed coherent explanatory narratives of stressful experiences aid children in their own emotional understanding and coping.

Finally, research on parent-child reminiscing about highly negative events has not found any gender differences. This suggests that when highly negative events occur, parents are just as concerned about helping their sons understand and cope as their daughters but in the context of everyday negative events, the kinds of stressful and emotional experiences we have on a daily basis, girls may be learning a more emotionally expressive style.

\section{Summary}

A substantial body of research has now established that children are learning the forms and functions of personal narratives through participating in parentguided reminiscing throughout early childhood. Children of more highly elaborative mothers come to tell more elaborative and coherent narratives of their own experiences by the end of the preschool years. Moreover, elaborative reminiscing is related to social and emotional aspects of the mother-child relationship. More highly elaborated reminiscing both emerges from and contributes to a more secure attachment relationship, such that more securely attached dyads are able to engage in more elaborated reminiscing, especially about emotion, and this kind of elaborative reminiscing reinforces and maintains secure attachment bonds. Moreover, elaborated reminiscing about emotion is linked to children's developing abilities to understand and regulate emotional experiences. Importantly, research has demonstrated that the reminiscing context per se is critical. Elaborated emotional reminiscing is more predictive of children developing emotional skills than motherchild conversations in other contexts. Reminiscing creates a shared history which bonds individuals together through time.

While the research base is impressive, there are also significant limitations. Most critically, the research has focused on mostly white, middle-class, Euro-American samples. The growing body of research on cultural differences has focused on eastern vs. western cultures, and has shown overall less elaborative reminiscing in collectivist cultures than autonomous cultures, but still show variability in reminiscing related to child outcome. Still, a great deal remains unknown. Research on 
oral based cultures would be informative, including Native American and Afro-American. In addition, we need to examine possible class differences in reminiscing style. The little research that exists suggests that class does not play a major role in reminiscing style (see Fivush et al., in press, for a review), but more information is needed. We also need to broaden the research to the extended family, including siblings and grandparents (see Pratt \& Fiese, 2004, for theory and some research on these issues), and to nontraditional families, including same-sex parent families. Finally, gender needs to be examined in more detail. While the findings that gender influences reminiscing are robust, exactly how or why reminiscing is gendered is less clear.

\section{Implications}

Overall, the research on maternal reminiscing style shows strong and consistent relations with children's developing memory and socio-emotional skills, and clear links between mother-child reminiscing and socio-emotional development. Autobiographical narratives are linked to self-understanding in at least three ways: self-definition, self-in-relation and self-regulation (Fivush et al., 2003).

In terms of self-definition, more highly elaborated maternal reminiscing helps children construct a more elaborated and coherent sense of self (Bird, Reese, \& Tripp, in press; Welch-Ross, Fasig, \& Farar, 1999). Moreover, families that engage in more highly elaborated reminiscing about their shared past have children who, as pre-adolescents, show higher levels of selfesteem and self-efficacy (Bohanek, Marin, Fivush, \& Duke, 2006). Thus an elaborative reminiscing style seems to facilitate children's developing understanding of self and helps children construct a more differentiated, more coherent and more positive sense of self across development.

In terms of self-in-relation, highly elaborated reminiscing both emerges from and contributes to the evolving attachment relationship between mother and child. By helping children construct more elaborated and coherent models of self and other, highly elaborated reminiscing helps children develop a sense of security in the world, and to view others as loving and trustworthy. Moreover, through creating a more detailed shared history, elaborated reminiscing creates more interweaving of self and other through time, creating more secure and more intricate connections with others.
Finally, in terms of self-regulation, the emotional content of mother-child reminiscing is critical. Children who engage in highly elaborated mother-guided reminiscing about their past experiences develop more advanced emotional understanding. A great deal of research has substantiated that preschool and school age children who show more limited emotional understanding are at risk for both internalizing and externalizing disorders, whereas more sophisticated emotional understanding predicts empathic and prosocial behavior. More specifically, elaborated reminiscing about emotional aspects of the past, especially reminiscing that focuses on the causes and explanations of emotional experiences has been clearly and consistently related to children's improved emotional understanding and regulation (Fivush \& Sales, 2006; Laible, 2004a, b; Sales \& Fivush, 2005). Mothers who are able to talk about emotional experiences, especially highly stressful events, with their children facilitate children's understanding of how and why these events occur and help their children to regulate the resulting negative affect.

As the research reviewed here indicates, the process of mother-child reminiscing is critical in children's developing understanding of self and emotion. It is as we share our experiences together, and as mothers help their young children to structure, remember and evaluate the experiences of their lives that children come to develop a sense of their past and of themselves.

\section{References}

Ackil, J. K., Van Abbema, D. L., \& Bauer, P. J. (2003). After the storm: Enduring differences in mother-child recollections of traumatic and nontraumatic events. Journal of Experimental Child Psychology, 84, 286-309.

Adams, S., Kuebli, J., Boyle, P., \& Fivush, R. (1995). Gender differences in parent-child conversations about past emotions: A longitudinal investigation. Sex Roles, 33, 309-323.

Bauer, P. J., \& Burch, M. M. (2004). Developments in early memory: Multiple mediators of foundational processes. In J. M. Lucariello, J. A. Hudson, R. Fivush, \& P.J. Bauer (Eds.), The development of the mediated mind (pp. 101-125). Mahwah, NJ: Lawrence Erlbaum.

Bauer, P., Steenes, L., \& Haight, J. (2003). Representation of the inner self in autobiography: Women's and men's use of internal states language in personal narratives. Memory, 11, $27-42$.

Bird, A., Reese, E., \& Tripp, G. Parent-child talk about past emotional events: Associations with child temperament and goodness-of-fit. Journal of Cognition and Development (in press).

Bohanek, J. G., Marin, K. A., Fivush, R., \& Duke, M. (2006). Family narrative interaction and children's self-understanding. Family Process, 45, 39-54. 
Bowlby, J. (1969). Attachment and loss: Vol. 1. Attachment. NY: Basic Books.

Bretherton, I., \& Mulholland, K. A. (1999). Internal working models in attachment relations: A construct revisited. In J. Cassidy, \& P. R. Shaver (Eds.), Handbook of attachment: Theory, research, and clinical applications (pp. 89-111). New York: Guilford.

Brody, L. (1999). Gender, emotion and the family. Cambridge, MA: Harvard University Press.

Buckner, J. P., \& Fivush, R. (1998). Gender and self in children's autobiographical narratives. Applied Cognitive Psychology, 12, 407-429.

Buckner, J. P., \& Fivush, R. (2000). Gendered themes in reminiscing. Memory, 8, 401-412.

Burger, L. K., \& Miller, P. J. (1999). Early talk about the past revisited: Affect in working-class and middle-class children's co-narrations. Journal of Child Language, 26, 133-162.

Davis, P. J. (1990). Gender differences in autobiographical memories for childhood emotional experiences. Journal of Personality and Social Psychology, 76, 498-510.

Farrant, K., \& Reese, E. (2000). Maternal style and children's participation in reminiscing: Stepping stones in children's autobiographical memory development. Journal of Cognition and Development, 1, 193-225.

Farrar, M. J., Fasig, L. G., \& Welch-Ross, M. K. (1997). Attachment and emotion in autobiographical memory development. Journal of Experimental Child Psychology, 67, 389-408.

Fischer, A.H. (2000). Gender and emotion: Social psychological perspectives. NY: Cambridge University Press.

Fivush, R. (1988). The functions of event memory: Some comments on Nelson and Barsalou. In U. Neisser, \& E. Winograd (Eds.), Remembering reconsidered: Ecological and traditional approaches to memory (pp. 277-282). New York: Cambridge University Press.

Fivush, R. (1991). Gender and emotion in mother-child conversations about the past. Journal of Narrative and Life History, $1,325-341$.

Fivush, R. (1998). Gendered narratives: Elaboration, structure and emotion in parent-child reminiscing across the preschool years. In C. P. Thompson, D. J. Herrmann, D. Bruce, J. D. Read, D. G. Payne, \& M. P. Toglia (Eds.), Autobiographical memory: Theoretical and applied perspectives (pp. 79-104). Mahwah, NJ: Erlbaum.

Fivush, R., Berlin, L., Sales, J. M., Mennuti-Washburn, J., \& Cassidy, J. (2003). Functions of parent-child reminiscing about emotionally negative events. Memory, 11, 179-192.

Fivush, R., Brotman, M., Buckner, J. P., \& Goodman, S. (2000). Gender differences in parent-child emotion narratives. Sex Roles, 42, 233-254.

Fivush, R., \& Buckner, J. P. (2000). Gender, sadness and depression: Developmental and socio-cultural perspectives. In A. H. Fischer (Eds.), Gender and emotion: Social Psychological perspectives (pp. 232-253). Cambridge, England: Cambridge University Press.

Fivush, R., \& Buckner J. (2003). Constructing gender and identity through autobiographical narratives. In R. Fivush, \& C. Haden (Eds.), Autobiographical memory and the construction of a narrative self: Developmental and cultural perspectives (pp. 149-167). Hillsdale, NJ: Erlbaum.

Fivush, R., \& Fromhoff, F. (1988). Style and structure in motherchild conversations about the past. Discourse Processes, 11, 337-355.

Fivush, R., \& Haden, C. A. (Eds.) (2003). Autobiographical memory and the construction of a narrative self: Develop- mental and cultural perspectives. Mahwah, NJ: Lawrence Erlbaum Associates.

Fivush, R., Haden, C., \& Reese, E. (1996). Remembering, recounting and reminiscing: The development of autobiographical memory in social context. In D. Rubin (Ed.), Reconstructing our past: An overview of autobiographical memory (pp. 341-359). New York: Cambridge University Press.

Fivush, R., Haden, C., \& Reese, E. Elaborating on elaborations: Maternal reminiscing style and children's cognitive and socioemotional outcome. Child Development (in press).

Fivush, R., \& Reese, E. (2002). Origins of reminiscing. In J. Webster, \& B. Haight (Eds.), Critical advances in reminiscence work (pp. 109-122). NY: Springer.

Fivush, R., \& Sales, J. M. (2006). Coping, attachment, and mother-child reminiscing about stressful events. MerrillPalmer Quarterly, 52, 125-150.

Fivush, R., \& Vasudeva, A. (2002). Remembering to relate: Socioemotional correlates of mother-child reminiscing. Journal of Cognition and Development, 3, 73-90.

Fivush, R., \& Wang, Q. (2005). Emotion talk in mother-child conversation of the shared past: The effects of culture, gender, and event valence. Journal of Cognition and Development, 6, 489-506.

Flannagan, D., Baker-Ward, L., \& Graham, L. (1995). Talk about preschool: Patterns of topic discussion and elaboration related to gender and ethnicity. Sex Roles, 32, 1-15.

Haden, C. (1998). Reminiscing with different children: Relating maternal stylistic consistency and sibling similarity in talk about the past. Developmental Psychology, 34, 99-114.

Haden, C. A., \& Fivush, R. (1996). Contextual variation in maternal conversational styles. Merrill-Palmer Quarterly, $42,200-227$.

Han, J. J., Leichtman, M. D., \& Wang, Q. (1998). Autobiographical memory in Korean, Chinese, and American children. Developmental Psychology, 34, 701-713.

Harley, K., \& Reese, E. (1999). Origins of autobiographical memory. Developmental Psychology, 35, 1338-1348.

Hayne, H., \& MacDonald, S. (2003). The socialization of autobiographical memory in children and adults: The roles of culture and gender. In R. Fivush, \& C. A. Haden (Eds.), Autobiographical memory and the construction of a narrative self: Developmental and cultural perspectives (pp. 99120). Mahwah, NJ: Lawrence Erlbaum.

Hoff-Ginsburg, E. (1991). Mother-child conversations in different social classes and communicative settings. Child Development, 62, 782-796.

Hudson, J. A. (1990). The emergence of autobiographic memory in mother-child conversation. In R. Fivush, \& J. A. Hudson (Eds.), Knowing and remembering in young children (pp. 166-196). New York: Cambridge University Press.

Kuebli, J., \& Fivush, R. (1992). Gender differences in parent-child conversations about past emotions. Sex Roles, 12, 683-698.

Laible, D. (2004a). Mother-child discourse in two contexts: Links with child temperament, attachment security, and socioemotional competence. Developmental Psychology, 40, 979-992.

Laible, D. (2004b). Mother-child discourse about a child's past behavior at 30-months and early socioemotional development at age 3. Merrill-Palmer Quarterly, 50, 159-180.

Laible, D., \& Thompson, R. (2000). Mother-child discourse, attachment security, shared positive affect, and early conscience development. Child Development, 71, 1424-1440.

Leichtman, M., Wang, Q., \& Pillemer, D.P. (2003). Cultural variation in interdependence and autobiographical memory. In R. Fivush, \& C. Haden (Eds.), Autobiographical memory 
and the construction of a narrative self: Developmental and cultural perspectives. Mahwah, NJ: Erlbaum.

MacDonald, S., Uesiliana, K., \& Hayne, H. (2000). Crosscultural and gender differences in childhood amnesia. Memory, 8, 365-376.

McAdams, D. P. (2001). The psychology of life stories. Review of General Psychology, 5, 100-122.

Melzi, G., \& Fernandez, C. (2004). Talking about past emotions: Conversations between Peruvian mothers and their preschool children. Sex Roles, 50, 641-657.

Mullen, M., \& Yi, S. (1995). The cultural context of talk about the past: Implications for the development of autobiographical memory. Cognitive Development, 10, 407-419.

Nelson, K., \& Fivush, R. (2004). The emergence of autobiographical memory: A social cultural developmental theory. Psychological Review, 111, 486-511.

Nolan-Hoeksema, S. (2002). Gender differences depression. In I. H. Gotlib, \& C. L. Hammen (Eds.), Handbook of depression (pp. 492-509). New York, NY: Guilford Press.

Oppenheim, D., Nir, A., Warren, S., \& Emde, R. N. (1997). Emotion regulation in mother-child narrative co-construction: Associations with children's narrative and adaptation. Developmental Psychology, 33, 284-294.

Pennebaker, J. W. (1997). Opening up. New York: Guilford.

Peterson, C., Jesso, B., \& McCabe, A. (1999). Encouraging narratives in preschoolers: An intervention study. Journal of Child Language, 26, 49-67.

Peterson, C., \& McCabe, A. (1992). Parental styles of narrative elicitation: Effect on children's narrative structure and content. First Language, 12, 299-321.

Pillemer, D. (1998). Momentous events, vivid memories. Cambridge: Harvard University Press.

Pratt, M. W., \& Fiese, B. E. (Eds.) (2004). Family Stories and the Lifecourse: Across Time and Generations. New York: Routledge.

Reese, E. (2002). Social factors in the development of autobiographical memory: The state of the art. Social Development, 11, 124-142.

Reese, E., Bird, A., \& Tripp, G. Children's self-esteem and moral self: Relationships with parent-child conversations about negative issues. Social Development (in press).
Reese, E., \& Brown, N. (2000). Reminiscing and recounting in the preschool years. Applied Cognitive Psychology, 14, 1-17.

Reese, E., \& Farrant, K. (2003). Origins of reminiscing parentchild relationships. In R. Fivush, \& C. A. Haden (Eds.), Autobiographical memory and the construction of a narrative self: Developmental and cultural perspectives (pp. 2948). Mahwah, NJ: Lawrence Erlbaum.

Reese, E., Haden, C. A., \& Fivush, R. (1993). Mother-child conversations about the past: Relationships of style and memory over time. Cognitive Development, 8, 403-430.

Reese, E., Haden, C., \& Fivush, R. (1996). Mothers, father, daughters, sons: Gender differences in reminiscing. Research on Language and Social Interaction, 29, 27-56.

Sales, J. M., \& Fivush, R. (2005). Social and emotional functions of mother-child reminiscing about stressful events. Social Cognition, 23, 70-90.

Sales, J.M., Fivush, R., \& Peterson, C. (2003). Parental reminiscing about positive and negative events. Journal of Cognition and Development, 4, 185-209.

Thompson, R. (2000). The legacy of early attachments. Child Development, 71, 145-152.

Wang, Q. (2001). "Did you have fun?": American and Chinese mother-child conversations about shared emotional experiences. Cognitive Development, 16, 693-715.

Wang, Q. (2003). Emotion situation knowledge in American and Chinese preschool children and adults. Cognition \& Emotion, 17(5), 725-746.

Wang, Q., \& Fivush, R. (2005). Mother-child conversations of emotionally salient events: Exploring the functions of reminiscing in Euro-American and Chinese families. Social Development, 14, 473-495.

Welch-Ross, M. K. (1997). Mother-child participation in conversation about the past: Relationship to preschoolers' theory of mind. Developmental Psychology, 33, 618-629.

Welch-Ross, M. K., Fasig, L., \& Farrar, M. J. (1999). Predictors of preschoolers' self-knowledge: Reference to emotion and mental states in mother-child conversation about past events. Cognitive Development, 14, 401-422. 